\title{
Relationship Between Job Dissatisfaction and Physical and Psychological Health Among Filipino Immigrants
}

\author{
A. B. de Castro, PhD, MSN, MPH, RN[Assistant Professor] \\ University of Washington School of Nursing, Seattle, WA \\ Gilbert C. Gee, PhD[Associate Professor] \\ University of California, Los Angeles School of Public Health, Los Angeles, CA \\ David Takeuchi, PhD[Professor and Associate Dean for Research] \\ University of Washington School of Social Work, Seattle, WA
}

\begin{abstract}
This study investigated the relationship between job dissatisfaction and psychological and physical health among Filipino immigrants in the United States. Cross-sectional data from the Filipino American Community Epidemiological Study were analyzed for 1,381 Filipino immigrants. The primary independent variable of interest was job dissatisfaction. Linear and negative binomial regression analyses were conducted to determine separate associations between job dissatisfaction and the outcomes of psychological distress and physical health conditions, respectively. Job dissatisfaction was positively associated with both psychological distress $(\beta=0.32, p<.001)$ and physical health conditions $(\beta=0.42, p<.001)$, controlling for sociodemographic variables such as age, gender, education, income, and job category. This community-based study demonstrated that job dissatisfaction has implications for health and well-being among an understudied, immigrant group of workers. Findings also suggest that job-related experiences should be considered when examining disparate health for immigrant, minority populations.
\end{abstract}

\begin{abstract}
The increased participation and visibility of minority and immigrant workers in workplaces throughout the United States has raised occupational health issues (Baker \& Stock, 2006; Baron \& Dorsey, 2006; Sum, Fogg, \& Harrington, 2002). Minority and immigrant workers typically fill jobs that are lower in wages and more dangerous and undesirable (American Federation of Labor, Congress of Industrial Organizations, 2005; La Veist, 2005; McCauley, 2005; Taylor \& Murray, 2006). Accordingly, they may encounter work-related circumstances that result in less satisfying jobs. For example, immigrant and minority workers are often assigned unfavorable job tasks or work shifts (de Castro, Fujishiro, Sweitzer, \& Oliva, 2006). Additionally, they may encounter prejudice or discrimination based on their race and ethnicity (de Castro, Gee, \& Takeuchi, in press). Immigrant workers in particular may experience limited job availability or occupational drift or demotion by working in jobs that are discordant with their academic or professional training (e.g., an immigrant physician driving a taxicab). These situations may significantly affect the meaningful experience of work and its impact on well-being.
\end{abstract}

\footnotetext{
Dr. Strasser is President, Partners in Business Health Solutions, Inc., Toledo, OH; and Adjunct Assistant Professor, University of Michigan, School of Nursing, Occupational Health Nursing Program, Ann Arbor, MI

Copyright of AAOHN Journal is the property of SLACK Incorporated and its content may not be copied or emailed to multiple sites or posted to a listserv without the copyright holer's express written permission. However, users may print, download, or email articles for individual use
} 


\section{JOB DISSATISFACTION}

Previous research has found that job dissatisfaction adversely affects both psychological and physical well-being. Job dissatisfaction is often used as a summary measure of workers' well-being because it captures both micro-level daily interactions on the job and macro-level factors related to selection into a job. Job dissatisfaction is associated with psychological problems, including emotional exhaustion, burnout, depression, anxiety, and anger, and physical conditions, including musculoskeletal disorders and cardiovascular disease, among a variety of worker populations (Fitzgerald, Haythornthwaite, Suchday, \& Ewart, 2003; Heslop, Smith, Metcalfe, Macleod, \& Hart, 2002; Jurado et al., 2005; Locker, 1996; Newbury-Birch \& Kamali, 2001; Piko, 2006; Svensen, Arnetz, Ursin, \& Eriksen, 2007; Williams et al., 1998). A meta-analysis conducted by Faragher, Cass, and Cooper (2005), based on 485 previous studies of job satisfaction and well-being, found that workers with low levels of job satisfaction were more likely to experience anxiety, depression, burnout, cardiovascular disease, musculoskeletal disorders, other physical illness, and reduced selfesteem. The literature suggests that job dissatisfaction is an important predictor of physical and psychological health. These studies, however, have not focused on minority or immigrant workers.

Although the general literature suggests that job dissatisfaction is associated with adverse outcomes, it is unclear whether this relationship may be found within minority or immigrant samples. Given the growing diversity of the U.S. work force, it is both timely and pertinent to examine how job dissatisfaction may be related to well-being in this population. More specifically, only a few studies of job dissatisfaction among Asian American workers have been reported (McNeely, 1987; Weaver, 2000, 2001). In a sample of Filipino nurses, nearly $10 \%$ reported job dissatisfaction (Berg, Rodriguez, Kading, \& De Guzman, 2004). Weaver and Hinson (2000), using a non-worksite-specific sample, found that Filipino Americans and other Asian Americans reported lower levels of satisfaction compared to European Americans. Further, they noted that Asian Americans from the Philippines, China, Japan, and India reported similar levels of job satisfaction and that differences were not statistically significant. Au, Garey, Bermas, and Chan (1998) compared job dissatisfaction between immigrant Chinese workers in midtown and uptown New York City restaurants versus Chinatown restaurants. Nearly two thirds of New York City workers reported being either moderately dissatisfied or very dissatisfied compared to $84 \%$ of Chinatown workers.

Asian Americans have become a significant part of the U.S. population due to both "push and pull" forces of immigration. As a group, they are one of the fastest growing segments of the American profile, projected to increase from 35.8 million in 2000 to 61.4 million in 2015 (U.S. Census Bureau, 2004). Reflecting this growth, participation of Asian Americans and immigrants in the U.S. labor pool is also rising. In particular, Filipinos are a large segment of the Asian work force, having a long history as laborers in the United States (Choy, 2003; Constable, 1997; Gonzalez, 1998; Scharlin \& Villanueva, 2000; Tyner, 1999). Filipino Americans are an understudied group. Yet, with 2.4 million Filipino American residents in the United States in 2000, they are the second largest Asian American group (Barnes \& Bennett, 2002). Moreover, after Mexico, the second largest foreign-born population in the United States is from the Philippines (Mosisa, 2002).

The goal of this study was to examine associations between job dissatisfaction and psychological and physical health in a community-based sample of Filipino immigrants in the United States. The researchers hypothesized that job dissatisfaction is associated with psychological distress and physical health problems. In conducting this study, several factors were considered that may confound these relationships, such as socioeconomic status, geographic region, and other sociodemographic factors. 


\section{METHODS}

\section{Participants}

These data were collected in the Filipino American Community Epidemiological Study (FACES), a community household survey conducted between 1998 and 1999 in Honolulu and San Francisco. Participants were randomly selected from households if they met the inclusion criteria of Filipino heritage and 18 years or older. The response rate was $78 \%$ and 2,285 individuals participated. Surveys were administered according to participants' language preference of English or one of two Filipino dialects (Tagalog or Ilocano).

The current analysis focused on 1,381 participants who self-identified as immigrant (not born in the United States) and reported they were working at the time of data collection. Data were weighted to adjust for differential probabilities of participant selection within a household and for neighborhood racial and economic characteristics. Additional details of the sample have been reported elsewhere (Gong, Gage, \& Tacata, 2003; Mossakowski, 2003).

\section{Measures}

The dependent variables of interest were psychological distress and physical health conditions. Psychological distress was measured with a subscale from the Symptom Checklist-90-Revised (SCL-90-R) (Derogatis, 1984, 1994; Derogatis \& Cleary, 1977; Derogatis, Lipman, \& Covi, 1973; Derogatis \& Savitz, 1999). The SCL-90-R is a wellestablished instrument that has been used broadly, primarily to assess a range of psychopathological symptoms and psychological problems, including psychological distress. Study participants were asked to rate their feelings and emotions in the past 30 days from 1 to 5 with a 20-item scale. Higher scores signified greater distress symptoms. Versions of the SCL-90-R have also been used cross-culturally in studies involving minority and immigrant samples, both internationally and in the United States (Aroian, Patsdaughter, Levin, \& Gianan, 1995; Asner-Self, Schreiber, \& Marotta, 2006; Bech et al., 1992; Takeuchi, Kuo, Kim, Leen, \& Leaf, 1989; Zheng, Xu, \& Shen, 1986).

Physical health conditions is a composite measure of a number of physical health problems. This measure was adapted from the Medical Outcome Study (MOS) (Stewart et al., 1989; Ware, 1995) and included a range of physical health problems, such as asthma, diabetes, hypertension, arthritis, physical disability, emphysema, neurological conditions, stomach ulcer, thyroid disease, and migraine headaches. Participants were asked to respond yes or no if they currently had any of the listed conditions. The range was 0 to 12 in this sample. Versions of the MOS have been used cross-culturally with immigrant and minority samples (Alonso et al., 2004; Lubetkin, Jia, \& Gold, 2003; Peek, Ray, Patel, Stoebner-May, \& Ottenbacher, 2004), including in prior studies of Filipino Americans specifically (de Castro et al., in press; Gee et al., 2006) and Asian Americans generally (Gee, Spencer, Chen, \& Takeuchi, 2007).

The primary independent variable of interest was job dissatisfaction. Participants rated the degree to which they were concerned about being dissatisfied with their jobs. Participants rated their degree of concern as 1 (none at all) to 4 (a lot). Single-item measures for job satisfaction have been examined previously for their utility and acceptability (Dolbier, Webster, McCalister, Mallon, \& Steinhardt, 2005; Wanous, Reichers, \& Hudy, 1997; Weaver \& Hinson, 2000). Consistent with prior research, job dissatisfaction scores in the current study were dichotomized into dissatisfied (some or a lot) versus not dissatisfied (none or a little). 
The analysis accounted for a variety of demographic and socioeconomic factors, including age in years, gender, marital status (married or not), and region of residence (San Francisco or Honolulu), that could confound associations between job dissatisfaction and psychological distress and physical health conditions. Age was controlled because older individuals may report more job satisfaction owing to having seniority and being more tolerant of working conditions than younger employees. Additionally, older workers tend to have greater morbidity. Gender was controlled because differences in job dissatisfaction may exist between men and women (Au et al., 1998).

Further, measures of socioeconomic status, including years of education, personal income level (less than $\$ 25,000, \$ 25,000$ to $\$ 49,999$, and $\$ 50,000$ and greater), and industry job category, were included. Individuals of higher socioeconomic status may report less job dissatisfaction and better health. Industry job category was derived from participants' selfreported job titles, which were then categorized according to the 2002 North American Industrial Classification System (NAICS) and subsequently collapsed into three primary groups: manual, trade, and service. Factors related to the immigrant experience, including years in the United States, primary language (English or Filipino dialect), and whether immigration had been for employment, were also controlled because the sample was composed of immigrants.

\section{Analysis}

The researchers began with exploratory data analysis, examining the distribution of study variables and correlations between study measures to ensure that variables were correctly specified. To examine whether job dissatisfaction was associated with distress, health conditions, and other participant characteristics (e.g., age or gender), the researchers used unadjusted bivariate analyses, testing statistical significance with $t$ tests. After these bivariate analyses, they considered if other factors confounded associations between job dissatisfaction and illness with regression modeling. For psychological distress, they used ordinary least squares regression. Because health conditions is a count, they used negative binomial regression, a type of Poisson modeling. All analyses were weighted to account for the sampling design. Finally, all continuous predictors were centered at their mean to facilitate interpretation of the intercept. That is, the intercept from the regression models referred to the predicted level of psychological distress for a respondent who was 42 years old with 12 years of education and 15 years in the United States (Aiken \& West, 1991).

\section{RESULTS}

Table 1 displays the characteristics of the study sample. Nearly $10 \%$ of the sample reported being dissatisfied with their jobs. On average, participants reported 0.86 health problems and a relatively low mean level of psychological distress (1.27 on a 1 to 5 scale). A majority $(89 \%)$ of respondents stated that a Filipino dialect was their primary daily language, and more than three fourths (77\%) had immigrated for employment reasons. Most (74\%) worked in service sector jobs and half earned less than $\$ 25,000$ per year. Respondents had approximately 12 years of education on average, and roughly half (54\%) resided in Honolulu. Their mean age was 42 years, approximately half (49\%) were female, and the majority were married $(65 \%)$.

Respondents dissatisfied with their jobs differed from those who were not dissatisfied in several ways (Table 1). Specifically, those dissatisfied reported more health conditions and psychological distress. They were also likely to be younger, unmarried, residing in San Francisco, of lower socioeconomic status, Filipino speaking, and less likely to have immigrated for work reasons. 
Table 1 provides evidence that respondents who were dissatisfied with their jobs were also less healthy. This association may be confounded by demographic and socioeconomic factors. Accordingly, regression analyses were used to examine whether job dissatisfaction is associated with distress and illness after accounting for potential confounders (Table 2). The regression models support the hypothesis that job dissatisfaction is associated with adverse psychological health and increased morbidity. Specifically, as shown by model 2 for both outcomes, individuals who reported job dissatisfaction were more likely to report psychological distress $(\beta=0.32, p<.001)$, even after accounting for age, gender, marital status, region, education, job category, income, language, years living in the United States, and whether immigration had been for employment. Similarly, job dissatisfaction was also associated with physical health conditions $(\beta=0.42, p<.001)$ in the expected direction, controlling for the same sociodemographic variables.

\section{DISCUSSION}

Results indicate that self-reported job dissatisfaction is associated with lower psychological and physical health among immigrant Filipino American workers. This finding is consistent with previously reported research on job satisfaction in primarily non-immigrant or White samples. Moreover, this study presents findings from a community sample; the majority of previous studies of job dissatisfaction focused on specific occupations, such as nurses, physicians, home care workers, and mental health professionals, and workplaces (Denton, Zeytinoglu, Davies, \& Lian, 2002; Evans et al., 2006; Johnson et al., 1995; Ma, Samuels, \& Alexander, 2003).

Immigrants may encounter circumstances that limit job availability and selection, such as documentation status, limited English proficiency, and ethnic discrimination. This, in turn, may direct or force them into undesirable jobs or jobs that do not match their aspirations or training, prompting dissatisfaction. Moreover, once in undesired or mismatched jobs, immigrants may face barriers that undermine successful and productive work experiences. de Castro et al. (2006) conducted a qualitative study that demonstrated how jobs were designed and managed in ways that were disadvantageous to immigrant workers. For example, workers reported they lacked training to perform job tasks safely in typically hazardous working conditions. Many workers reported employers would not compensate them according to agreed on wage rates or forced them to work overtime and threatened termination. Although the current study does not specifically provide information about these issues, it is possible that similar circumstances were experienced by Filipino immigrants in this sample. Future studies of job dissatisfaction should examine the reasons workers are dissatisfied.

Approximately 1 in 10 Filipino American workers reported job dissatisfaction. This level of dissatisfaction is similar to levels for the general U.S. population. For example, a recent Gallup poll indicated that $9 \%$ of Americans disliked their jobs. Dembe, Erickson, and Delbos (2004), studying a nationally representative sample of U.S. workers aged 33 to 41, found that $17.1 \%$ of adults with a work-related injury and $7.2 \%$ without a work-related injury were dissatisfied with their jobs. Thus, estimates of job dissatisfaction in this study are similar to other recent studies of the general U.S. population.

Most importantly, job dissatisfaction was associated with higher levels of psychological distress and more physical health conditions. Lipscomb, Loomis, McDonald, Argue, and Wing (2006) suggested that work-related factors and consequents contribute to health disparities. Job dissatisfaction may operate as a proxy for other work-related stressors and be associated with numerous employee outcomes, including absenteeism, turnover, and burnout (Farrell, 1983; Hom \& Kinicki, 2001). Future studies should investigate how global 
measures, including dissatisfaction, as well as specific measures of the work process, such as job autonomy, are associated with health among immigrant workers. In so doing, it would be important to capture aspects of the work environment not traditionally measured in most studies of worker health, including adjustment to a new work culture, racial discrimination, concerns over worker visas, and language barriers.

A key contribution of this study is the investigation of an understudied group. Considering that minorities and immigrants, particularly those of Asian descent, make up a growing percentage of the U.S. labor force, investigating how working in the United States impacts health and well-being in this population is pertinent. More than three fourths (77\%) of the sample came to the United States primarily for employment. Job dissatisfaction may have a profound impact on well-being for this group. If work and employment has considerable importance for these immigrants (i.e., they leave their home country for it), then the level of satisfaction they derive from it should not be underestimated. These findings indicate that job dissatisfaction is germane when examining psychological and physical health outcomes for this population.

These study findings should be viewed as preliminary. Although the primary variable of interest was job dissatisfaction, these data do not provide detailed information on the facets of respondents' jobs that were not satisfying. Further research about the factors that may contribute to job dissatisfaction, such as those related to work organization, job quality, job strain, and hazardous exposures, among samples of minority and immigrant workers is necessary. To compare the results to prior research, the investigators employed a single-item measure of dissatisfaction. This global marker appeared useful, but future research should capture specific dimensions of dissatisfaction (e.g., dissatisfaction with coworkers, income, or job tasks). Additionally, because self-reported job titles were collapsed into manufacturing, trade, and service, the researchers recognized that reasons individuals were dissatisfied with their jobs could vary within each category. Research with a sample of workers from a specific type of job or workplace may provide some commonalities of occupation-related factors that contribute to job dissatisfaction. Rather, this study used a community sample, providing a unique way to examine an occupational health issue. The results demonstrate that associations between job dissatisfaction and psychological and physical health outcomes are meaningful across a wide range of job titles among immigrant Filipinos. It is recommended that community-based samples continue to be used to investigate occupational health issues, particularly among minority and immigrant groups. However, community-based studies tend to find lower levels of job dissatisfaction compared to occupation-specific studies. For example, a survey of Filipino seafarers found that $25 \%$ were dissatisfied (Allen \& Gough, 2006). The higher levels in occupation-specific studies may result from respondents being "primed" to think critically about their occupations, whereas more general-purpose studies may not provide such priming. This is not a limitation per se, but future studies should take this context effect into account. Finally, this study is based on cross-sectional data. Thus, although the literature suggests that job dissatisfaction leads to deficits in well-being, it is also possible that individuals who are distressed or physically ill become more dissatisfied in their jobs. Hence, an important next step is to replicate these analyses with longitudinal data. In addition, future studies should evaluate whether the relationship between job dissatisfaction and physical and psychological health is similar across ethnic groups. That said, this study provides important initial evidence from which to direct future study.

\section{IMPLICATIONS FOR OCCUPATIONAL HEALTH NURSES}

Recognition and awareness of job dissatisfaction among groups of workers is important for occupational health nurses. Being dissatisfied with one's job has adverse implications for 
psychological and physical health, which, in turn, can affect productivity at work.

Occupational health nurses, having primary responsibility for the health and well-being of workers, can attempt to prevent poor health outcomes by assessing job dissatisfaction and identifying reasons for it. Assessment should occur at both the individual worker and group levels (e.g., department or shift).

Understanding why workers are dissatisfied with their jobs assists occupational health nurses to better meet workers' needs. For example, referral to an employee assistance program may be indicated. Occupational health nurses can communicate workers' collective reasons for dissatisfaction to those who can intervene and take positive corrective action. For example, if employees are dissatisfied because the physical work environment is not ergonomically designed, the occupational health nurse can partner with an ergonomist to institute needed modifications. Also, if workers are dissatisfied with ventilation and air quality in a manufacturing setting, occupational health nurses can collaborate with industrial hygienists to alleviate the problem.

Because a dissatisfied work force is likely to be less healthy physically and psychologically, occupational health nurses may invest in health promotion efforts (e.g., weight management, hypertension control, and smoking cessation) to counter the effects of dissatisfaction. The costs to implement primary and secondary prevention programs are small compared to the costs of tertiary prevention programs (e.g., treatment and rehabilitation), and the programs may increase worker productivity. Moreover, directly preventing or reducing worker dissatisfaction may be more cost-effective in the long-term.

Further, occupational health nurses must interact with an increasingly diverse work force. Workers from different racial or ethnic and cultural backgrounds and of immigrant status may have distinct concerns and needs within the workplace. For example, if worker training on health and safety is provided only in English, non-native English speakers will not benefit from this information. Occupational health nurses can play a critical role as worker advocates in such cases. They can investigate alternative training resources that accommodate workers' language needs. Workers' dissatisfaction may also result from discrimination. In this case, occupational health nurses might implement programs to reduce interpersonal prejudice and inequities in pay and work tasks. As the frontline health care professionals, occupational health nurses must actively learn about the work force, particularly when that work force is multicultural.

\section{CONCLUSION}

This community-based study found that job dissatisfaction has implications for both physical and psychological well-being among an understudied, minority, immigrant group of workers. Findings suggest that job- and work-related experiences that contribute to dissatisfaction are important in terms of identifying threats to health. Job dissatisfaction may be important in explaining health disparities between Whites and minority populations. Occupational health nurses can play a key role in the prevention of disease by assessing, identifying, and correcting workplace factors creating dissatisfying jobs.

\section{IN SUMMARY}

\section{Relationship Between Job Dissatisfaction and Physical and Psychological Health} Among Filipino Immigrants

1. Job dissatisfaction has adverse implications for psychological and physical health, which, in turn, can affect work productivity. 
2. Occupational health nurses must understand why workers are dissatisfied with their jobs or the workplace to assist in efforts to better meet workers' needs.

3. A dissatisfied work force is likely to be less healthy physically and psychologically, increasing the need for health promotion programs and the resources to pay for them.

4. The increasing diversity and multicultural profile of the american work force poses challenges requiring understanding of and respect for the distinct needs of workers.

\section{REFERENCES}

Aiken, LS.; West, SG. Multiple regression: Testing and interpreting interactions. Sage Publications; Thousand Oaks, CA: 1991.

Allen, SD.; Gough, A. A sociocultural assessment of Filipino crew members working in the Hawaiibased longline fleet. U.S. Department of Commerce; Washington, DC: 2006. NOAA Technical Memo NOAA-TMNMFS-PIFSC-6, 1-52

Alonso J, Ferrer M, Bandek B, Ware JE, Aaronson NK, Mosconi P, et al. Health-related quality of life associated with chronic conditions in eight countries: Results from the International Quality of Life Assessment (IQOLA) Project. Quality of Life Research 2004;13(2):283-298. [PubMed: 15085901]

American Federation of Labor, Congress of Industrial Organizations. Immigrant workers at risk: The urgent need for improved workplace safety and health policies and programs. 2005. Retrieved July 2, 2007, from www.aflcio.org/aboutus/laborday/upload/immigrant_risk.pdf

Aroian KJ, Patsdaughter CA, Levin A, Gianan ME. Use of the Brief Symptom Inventory to assess psychological distress in three immigrant groups. International Journal of Social Psychiatry 1995;41(1):31-46. [PubMed: 7622339]

Asner-Self KK, Schreiber JB, Marotta SA. A cross-cultural analysis of the Brief Symptom Inventory-18. Cultural Diversity and Ethnic Minority Psychology 2006;12(2):367-375. [PubMed: 16719583]

Au AYW, Garey JG, Bermas N, Chan MM. The relationship between acculturation and job satisfaction among Chinese immigrants in the New York City restaurant business. Hospitality Management 1998;17(1):11-21.

Baker, R.; Stock, L. Labor unions: Their role in occupational and environmental health. In: Levy, BS.; Wegman, DH.; Baron, SL.; Sokas, RK., editors. Occupational and environmental health: Recognizing and preventing disease and injury. Lippincott Williams \& Wilkins; Philadelphia: 2006. p. 697-709.

Barnes, JS.; Bennett, CE. The Asian population: 2000. Census brief 2000. 2002. (C2KBR/01-16). Retrieved July 2, 2007, from www.census.gov/prod/2002pubs/ c2kbr01-16.pdf

Baron, SL.; Dorsey, JW. Disparities in occupational and environmental exposures and health. In: Levy, BS.; Wegman, DH.; Baron, SL.; Sokas, RK., editors. Occupational and environmental health: Recognizing and preventing disease and injury. Lippincott Williams \& Wilkins; Philadelphia: 2006. p. 641-660.

Bech P, Allerup P, Maier W, Albus M, Lavori P, Ayuso JL. The Hamilton scales and the Hopkins Symptom Checklist (SCL-90): A cross-national validity study in patients with panic disorders. British Journal of Psychiatry 1992;160:206-211. [PubMed: 1540760]

Berg JA, Rodriguez D, Kading V, De Guzman C. Demographic survey of Filipino American nurses. Nursing Administration Quarterly 2004;28(3):199-206. [PubMed: 15446608]

Choy, CC. Empire of care: Nursing and migration in Filipino American history. Duke University Press; Durham, NC: 2003.

Constable, N. Maid to order in Hong Kong: An ethnography of Filipino workers. Cornell University Press; Ithaca, NY: 1997. 
de Castro AB, Fujishiro K, Sweitzer E, Oliva J. How immigrant workers experience workplace problems: A qualitative study. Archives of Environmental and Occupational Health 2006;61(6): 249-258. [PubMed: 17967746]

de Castro AB, Gee GC, Takeuchi DT. Workplace discrimination and health among Filipinos in the U.S. American Journal of Public Health. in press.

Dembe AE, Erickson JB, Delbos R. Predictors of work-related injuries and illness: National survey findings. Journal of Occupational and Environmental Hygiene 2004;1(8):542-550. [PubMed: 15238307]

Denton M, Zeytinoglu IU, Davies S, Lian J. Job stress and job dissatisfaction of home care workers in the context of health care restructuring. International Journal of Health Services 2002;32(2):327357. [PubMed: 12067035]

Derogatis, L. SCL-90-R manual: II. Administration, scoring and procedures. Clinical Psychometrics Research Unit; Towson, MD: 1984.

Derogatis, LR. Symptom Checklist-90-R. National Computer Systems; Minneapolis, MN: 1994.

Derogatis LR, Cleary PA. Confirmation of the dimensional structure of the SCL-90: A study in construct validation. Journal of Clinical Psychology 1977;33:981-989.

Derogatis LR, Lipman RS, Covi L. SCL-90: An outpatient psychiatric rating scale. Preliminary report. Psycho-pharmacology Bulletin 1973;9(1):13-28.

Derogatis, LR.; Savitz, KL. The SCL-90-R, Brief Symptom Inventory, and matching clinical rating scales. In: Maruish, ME., editor. The use of psychological testing for treatment planning and outcomes assessment. Erlbaum; Mahwah, NJ: 1999. p. 679-724.

Dolbier CL, Webster JA, McCalister KT, Mallon MW, Steinhardt MA. Reliability and validity of a single-item measure of job satisfaction. American Journal of Health Promotion 2005;19(3):194198. [PubMed: 15693347]

Evans S, Huxley P, Gately C, Webber M, Mears A, Pajak S, et al. Mental health, burnout and job satisfaction among mental health social workers in England and Wales. British Journal of Psychiatry 2006;188:75-80. [PubMed: 16388074]

Faragher EB, Cass M, Cooper CL. The relationship between job satisfaction and health: A metaanalysis. Occupational and Environmental Medicine 2005;62(2):105-112. [PubMed: 15657192]

Farrell D. Exit, voice, loyalty, and neglect as responses to job dissatisfaction: A multidimensional scaling study. The Academy of Management Journal 1983;26(4):596-607.

Fitzgerald ST, Haythornthwaite JA, Suchday S, Ewart CK. Anger in young black and white workers: Effects of job control, dissatisfaction, and support. Journal of Behavioral Medicine 2003;26(4): 283-296. [PubMed: 12921005]

Gee GC, Chen J, Spencer MS, See S, Kuester OA, Tran D, et al. Social support as a buffer for perceived unfair treatment among Filipino Americans: Differences between San Francisco and Honolulu. American Journal of Public Health 2006;96(4):677-684. [PubMed: 16507727]

Gee GC, Spencer MS, Chen J, Takeuchi D. A nationwide study of discrimination and chronic health conditions among Asian Americans. American Journal of Public Health 2007;97(7):1275-1282. [PubMed: 17538055]

Gong F, Gage S-J, Tacata LA. Helpseeking behavior among Filipino Americans: A cultural analysis of face and language. Journal of Community Psychology 2003;31(5):469-488.

Gonzalez, JL. Philippine labour migration. Institute of Southeast Asian Studies; Singapore: 1998.

Heslop P, Smith GD, Metcalfe C, Macleod J, Hart C. Change in job satisfaction, and its association with self-reported stress, cardiovascular risk factors and mortality. Social Science and Medicine 2002;54(10):1589-1599. [PubMed: 12061489]

Hom PW, Kinicki AJ. Toward a greater understanding of how dissatisfaction drives employee turnover. The Academy of Management Journal 2001;44(5):975-987.

Johnson JV, Hall EM, Ford DE, Mead LA, Levine DM, Wang NY, et al. The psychosocial work environment of physicians: The impact of demands and resources on job dissatisfaction and psychiatric distress in a longitudinal study of Johns Hopkins Medical School graduates. Journal of Occupational and Environmental Medicine 1995;37(9):1151-1159. [PubMed: 8528725] 
Jurado D, Gurpegui M, Moreno O, Fernandez MC, Luna JD, Galvez R. Association of personality and work conditions with depressive symptoms. European Psychiatry: The Journal of the Association of European Psychiatrists 2005;20(3):213-222. [PubMed: 15935419]

La Veist, TA. Hispanic/Latino health issues. In: La Veist, TA., editor. Minority populations and health. Jossey-Bass; San Francisco: 2005. p. 260-279.

Lipscomb HJ, Loomis D, McDonald MA, Argue RA, Wing S. A conceptual model of work and health disparities in the United States. International Journal of Health Services 2006;36(1):25-50. [PubMed: 16524164]

Locker D. Work stress, job satisfaction and emotional well-being among Canadian dental assistants. Community Dentistry and Oral Epidemiology 1996;24(2):133-137. [PubMed: 8654035]

Lubetkin EI, Jia H, Gold MR. Use of the SF-36 in low-income Chinese American primary care patients. Medical Care 2003;41(4):447-457. [PubMed: 12665709]

Ma CC, Samuels ME, Alexander JW. Factors that influence nurses' job satisfaction. Journal of Nursing Administration 2003;33(5):293-299. [PubMed: 12792284]

McCauley LA. Immigrant workers in the United States: Recent trends, vulnerable populations, and challenges for occupational health. AAOHN Journal 2005;53(7):313-319. [PubMed: 16097105]

McNeely RL. Job satisfaction and other characteristics of Asian American human service workers. Social Work Research and Abstracts 1987;23(4):7-9.

Mosisa AT. The role of foreign-born workers in the U.S. economy. Monthly Labor Review 2002;125(5):3-14.

Mossakowski KN. Coping with perceived discrimination: Does ethnic identity protect mental health? Journal of Health and Social Behavior 2003;44(3):318-331. [PubMed: 14582311]

Newbury-Birch D, Kamali F. Psychological stress, anxiety, depression, job satisfaction, and personality characteristics in preregistration house officers. Postgraduate Medical Journal 2001;77(904):109-111. [PubMed: 11161078]

Peek MK, Ray L, Patel K, Stoebner-May D, Ottenbacher KJ. Reliability and validity of the SF-36 among older Mexican Americans. The Gerontologist 2004;44(3):418-425. [PubMed: 15197296]

Piko BF. Burnout, role conflict, job satisfaction and psychosocial health among Hungarian health care staff: A questionnaire survey. International Journal of Nursing Studies 2006;43(3):311-318. [PubMed: 15964005]

Scharlin, C.; Villanueva, LV. Philip Vera Cruz: A personal history of Filipino immigrants and the farmworkers movement. University of Washington Press; Seattle, WA: 2000.

Stewart AL, Greenfield S, Hays RD, Wells K, Rogers WH, Berry SD, et al. Functional status and wellbeing of patients with chronic conditions: Results from the Medical Outcomes Study. JAMA: Journal of the American Medical Association 1989;262(7):907-913.

Sum, A.; Fogg, N.; Harrington, P. Immigrant workers and the great American job machine: The contributions of new foreign immigration to national and regional labor force growth in the 1990s. Northeastern University, Center for Labor Market Studies; Boston: 2002.

Svensen E, Arnetz BB, Ursin H, Eriksen HR. Health complaints and satisfied with the job? A crosssectional study on work environment, job satisfaction, and subjective health complaints. Journal of Occupational and Environmental Medicine 2007;49(5):568-573. [PubMed: 17495699]

Takeuchi DT, Kuo H, Kim K, Leen H, Leaf PJ. Psychiatric symptom dimensions among Asian Americans and native Hawaiians: An analysis of the symptom checklist. Journal of Community Psychology 1989;17(4):319-329.

Taylor, AK.; Murray, LR. Occupational safety and health. In: Levy, BS.; Sidel, VW., editors. Social injustice and public health. Oxford University Press; Oxford: 2006. p. 337-356.

Tyner JA. The global context of gendered labor migration from the Philippines to the United States. The American Behavioral Scientist 1999;42(4):671-689.

U.S., Census Bureau. Census Bureau projects tripling of Hispanic and Asian populations in 50 years; Non-Hispanic Whites may drop to half of total population. 2004. Retrieved July 8, 2007, from www.census.gov/Press-Release/www/releases/archives/population/001720.html

Wanous JP, Reichers AE, Hudy MJ. Overall job satisfaction: How good are single-item measures? Journal of Applied Psychology 1997;82(2):247-252. [PubMed: 9109282] 
Ware JE. The status of health assessment. Annual Review of Public Health 1995;16:327-354.

Weaver CN. The effect of being born in the United States on the job satisfaction of Asian Americans. Psychological Reports 2000;87(1):347-350. [PubMed: 11026437]

Weaver CN. Contribution of job satisfaction to happiness among Asian Americans. Psychological Reports 2001;89(1):191-198. [PubMed: 11729542]

Weaver CN, Hinson S. Job satisfaction of Asian Americans. Psychological Reports 2000;86(2):586594. [PubMed: 10840916]

Williams RA, Pruitt SD, Doctor JN, Epping-Jordan JE, Wahlgren DR, Grant I, et al. The contribution of job satisfaction to the transition from acute to chronic low back pain. Archives of Physical Medicine and Rehabilitation 1998;79(4):366-374. [PubMed: 9552100]

Zheng YP, Xu LY, Shen QJ. Styles of verbal expression of emotional and physical experiences: A study of depressed patients and normal controls in China. Culture, Medicine and Psychiatry 1986;10(3):231-243. 


\section{Table 1}

Descriptive statistics by Job Dissatisfaction and for the entire sample

\begin{tabular}{|c|c|c|c|}
\hline & \multicolumn{2}{|c|}{ Job Dissatisfaction } & \multirow[b]{2}{*}{ Entire Sample } \\
\hline & No $(N=1,248)$ & Yes $(N=133)$ & \\
\hline Psychological distress & $1.23(0.37)$ & $1.65(0.56)$ & $1.27(0.41)$ \\
\hline Health conditions & $0.80(1.17)$ & $1.33(1.54)$ & $0.86(1.22)$ \\
\hline Age (years) & $42.37(11.83)$ & $39.92(12.23)^{*}$ & $42.12(11.89)$ \\
\hline Female & $47.8 \%$ & $59.1 \%$ & $48.9 \%$ \\
\hline Married & $65.9 \%$ & $57.5 \% *$ & $65.1 \%$ \\
\hline San Francisco & $43.5 \%$ & $71.4 \%{ }^{* *}$ & $46.3 \%$ \\
\hline Education (years) & $11.74(4.99)$ & $12.41(5.23)$ & $11.81(5.02)$ \\
\hline \multicolumn{4}{|l|}{ Industry job category } \\
\hline Manual & $16.9 \%$ & $10.7 \%$ & $15.1 \%$ \\
\hline Trade & $9.4 \%$ & $13.8 \%$ & $10.5 \%$ \\
\hline Service & $73.7 \%$ & $75.5 \%$ & $74.4 \%$ \\
\hline \multicolumn{4}{|l|}{ Personal income } \\
\hline$<\$ 25,000$ & $51.2 \%$ & $41.7 \%$ & $50.3 \%$ \\
\hline$\$ 25,000-\$ 49,999$ & $30.9 \%$ & $43.6 \%{ }^{*}$ & $32.2 \%$ \\
\hline$\geq \$ 50,000$ & $13.0 \%$ & $10.7 \%$ & $12.8 \%$ \\
\hline Missing & $4.9 \%$ & $4.0 \%$ & $4.7 \%$ \\
\hline \multicolumn{4}{|l|}{ Daily language } \\
\hline Filipino & $90.9 \%$ & $75.0 \%{ }^{* *}$ & $89.4 \%$ \\
\hline English & $9.1 \%$ & $25.0 \%$ & $10.6 \%$ \\
\hline Immigrated for employment & $79.2 \%$ & $59.3 \% * *$ & $77.2 \%$ \\
\hline Years in the United States & $14.66(9.62)$ & $15.91(9.16)$ & $14.79(9.58)$ \\
\hline $\begin{array}{l}\text { Note. Values are mean (SD). } \\
* \quad p<.05 \text {. }\end{array}$ & & & \\
\hline$* * p<.001$ & & & \\
\hline
\end{tabular}


Table 2

Results of Regression Analyses for Psychological Distress and Health Conditions

\begin{tabular}{|c|c|c|c|c|}
\hline & \multicolumn{2}{|c|}{ Psychological Distress } & \multicolumn{2}{|c|}{ Health Conditions } \\
\hline & Model 1 & Model 2 & Model 1 & Model 2 \\
\hline Age (years) & $-0.002(0.001)^{*}$ & $-0.002(0.001)^{*}$ & $0.026(0.004)^{* *}$ & $0.026(0.004)^{* *}$ \\
\hline Female & $0.094(0.023)^{* *}$ & $0.087(0.022)^{* *}$ & $0.161(0.081)^{*}$ & $0.148(0.08)$ \\
\hline Married & $-0.037(0.026)$ & $-0.033(0.025)$ & $0.18(0.089)^{*}$ & $0.179(0.089)^{*}$ \\
\hline San Francisco & $0.347(0.031)^{* *}$ & $0.314(0.030)^{* *}$ & $0.724(0.112)^{* *}$ & $0.689(0.112)^{* *}$ \\
\hline Education (years) & $-0.002(0.002)$ & $-0.001(0.002)$ & $-0.007(0.01)$ & $-0.006(0.01)$ \\
\hline \multicolumn{5}{|c|}{ Industry job category Manual (reference) } \\
\hline Trade & $0.045(0.042)$ & $0.033(0.039)$ & $0.207(0.179)$ & $0.194(0.179)$ \\
\hline Service & $0.016(0.026)$ & $0.012(0.025)$ & $0.113(0.118)$ & $0.109(0.114)$ \\
\hline \multicolumn{5}{|l|}{ Income } \\
\hline \multicolumn{5}{|l|}{$<\$ 25,000$ (reference) } \\
\hline$\$ 25,000-\$ 49,999$ & $-0.001(0.034)$ & $-0.003(0.033)$ & $-0.095(0.01)$ & $-0.093(0.098)$ \\
\hline$\geq \$ 50,000$ & $-0.08(0.043)$ & $-0.063(0.043)$ & $-0.302(0.136)^{*}$ & $-0.269(0.135)^{*}$ \\
\hline Missing & $0.016(0.06)$ & $0.034(0.056)$ & $-0.388(0.196)^{*}$ & $-0.362(0.188)^{*}$ \\
\hline \multicolumn{5}{|l|}{ Daily language } \\
\hline \multicolumn{5}{|l|}{ Filipino (reference) } \\
\hline English & $0.05(0.042)$ & $0.017(0.039)$ & $0.076(0.133)$ & $0.039(0.131)$ \\
\hline Immigrated for employment & $0.027(0.032)$ & $0.041(0.031)$ & $0.017(0.101)$ & $0.049(0.097)$ \\
\hline Years in the United States & $0.002(0.001)$ & $0.002(0.001)$ & $0.01(0.005)^{*}$ & $0.01(0.004)^{*}$ \\
\hline Job dissatisfaction & & $0.316(0.049)^{* *}$ & & $0.419(0.115)^{* *}$ \\
\hline Intercept & $1.055(0.045)^{* *}$ & $1.035(0.044)^{* *}$ & $-0.867(0.173)^{* *}$ & $-0.917(0.169)^{* *}$ \\
\hline \multicolumn{5}{|l|}{ Note. Values are $\beta$ (SE $\beta)$. } \\
\hline \multicolumn{5}{|l|}{$*^{*}<<.05}$. \\
\hline$* * * 0.001$. & & & & \\
\hline
\end{tabular}

